\title{
Motivação para ler e Compreensão Leitora de Estudantes do Ensino Fundamental
}

\author{
Ana Paula Bonfim Hirai, Evely Boruchovitch.
}

\section{Resumo}

A motivação para leitura e a compreensão leitora são apontadas pela literatura como importantes na predição da aprendizagem e do desempenho escolar bem sucedidos. Considerando a relevância de se conhecer melhor essas variáveis entre alunos da Educação Básica, o presente projeto de pesquisa deu continuidade a projetos anteriores da professora orientadora, financiados pelo CNPq. A amostra foi composta de aproximadamente 65 estudantes de ambos os sexos e entre os anos do 6 ao 9 ano de uma escola da rede particular do munícipio de Piracicaba/SP. Os dados foram coletados primeiramente por meio de uma Escala de Motivação para Leitura, seguido de um teste de Cloze para avaliar a compreensão leitora. O desempenho escolar foi aferido pelos conceitos de português e matemática dos alunos. Antes da coleta de dados, foram explicados os objetivos da pesquisa, e informado que ela não influenciaria as notas na escola. Os dados foram codificados e examinados pelos procedimentos da Estatística Descritiva e Inferencial.

\section{Palavras-chave:}

Motivação para ler e Compreensão Leitora de Estudantes do Ensino Fundamental.

\section{Introdução}

A aprendizagem nos dias de hoje exige que o aluno seja capaz de se autorregular e se responsabilizar pelo seu próprio processo de aprendizagem. A autorregulação da aprendizagem é um construto complexo, muito relacionado ao sucesso escolar e acadêmico. Tanto a motivação para leitura quanto a compreensão leitora, são importantes fatores que influenciam positivamente na aprendizagem e no desempenho escolar do aluno. Neste sentido, os objetivos do estudo são: caracterizar a motivação para leitura e a compreensão leitora de estudantes de 6음 ao ano do Ensino Fundamental de escolas públicas e/ou particulares de Piracicaba; explorar relações entre a motivação para leitura, a compreensão leitora e o desempenho escolar dos participantes.

\section{Resultados e Discussão}

Os dados revelaram que a motivação extrínseca autônoma para a leitura prevaleceu entre os participantes, seguida da motivação intrínseca (Tabela 1). Assim, os alunos relataram, predominantemente ler de forma espontânea e demonstraram reconhecer o valor e a utilidade da leitura tanto para a sua vida social, como escolar. Constatou-se também que 56 alunos apresentaram nível de leitura independente, e 9 alunos o nível médio. Observou-se ainda que a motivação para ler e a compreensão leitora dos participantes tenderam a aumentar com a progressão da idade e do ano escolar (Tabela 2). No que diz respeito ao desempenho escolar, a maioria doa alunos está acima da média tanto em Português (81.54\%) quanto em matemática (80\%). Os dados possibilitam inferir que os alunos que apresentam bom desempenho escolar tendem a possuir motivação intrínseca ou extrínseca autônoma de leitura e um nível independente ou médio de leitura.
Tabela 1. Motivação para leitura dos alunos em relação ao ano escolar

\begin{tabular}{|c|c|c|c|c|c|c|c|}
\hline Tipo & 60ano & $7^{\circ} a$ & no & $8 \div a$ & ino & 99ano & Total \\
\hline Motiv & N \% & $\mathbf{N}$ & $\%$ & $\mathbf{N}$ & $\%$ & N \% & N \% \\
\hline Desmot & 211.4 & 4 & 21 & 3 & 17.7 & 433.3 & 1320 \\
\hline Extr.Con & 15.9 & 1 & 5.3 & - & - & - & 23.1 \\
\hline Extr.Aut & 1165 & 9 & 47.4 & 10 & 58.8 & 325 & 3350.8 \\
\hline Intriseca & 317.7 & 5 & 26.3 & 4 & 23.5 & $\begin{array}{ll}5 & 41.7\end{array}$ & 1726.1 \\
\hline Total & 17100 & 19 & 100 & 17 & 100 & 12100 & 65100 \\
\hline
\end{tabular}

Tabela 2. Níveis de leitura dos alunos em relação ao ano escolar

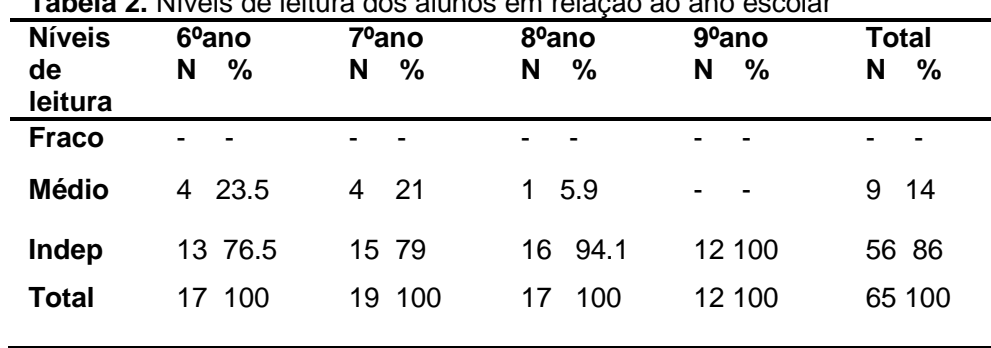

\section{Conclusões}

Com base na literatura da área e nos resultados dessa pesquisa, conclui-se que a motivação intrínseca para a leitura e a compreensão leitora dos alunos tendem a melhorar com o passar dos anos escolares. Ambas variáveis estudadas influenciam no desempenho escolar, visto que auxiliam nos processos cognitivos complexos da autorregulação. $\mathrm{O}$ estudante, estando motivado e possuindo uma boa compreensão leitora poderá evitar problemas como o fracasso escolar ou as dificuldades de apreensão dos conteúdos.

\section{Agradecimentos}

Agradecimentos a CNPq, à Prof ${ }^{a}$ Dra Evely Boruchovitch, à escola e aos alunos que participaram dessa pesquisa.

Gomes, M. A. M., Boruchovitch, E.- Escala de Motivação para a Leitura para Estudantes do Ensino Fundamental: Construção e Validação Psicologia Reflexão e Crítica, 2015.

Boruchovitch, E.- Algumas estratégias de compreensão em leitura de alunos do Ensino Fundamental, Psicologia Escolar e Educacional, 2001. 